\title{
Teaching Medical Gerontology in Europe
}

\author{
Group of European Professors in Medical Gerontology (GEPMG)*
}

The very old comprise the fastest growing population group in all European countries and declining birth rates are causing an even greater increase in the proportion of old people in the population. It is estimated that the number of people aged over 80 in Europe will double within the next 25 to 30 years [1]. In Germany alone it is suggested that there will be 12000 centenarians in the year 2000 [2].

In old age illness is a major threat to well-being and autonomy. There is growing awareness that the needs of old people are as many and as varied and even more medical in nature than those of younger age groups. Old people are able to benefit disproportionately from advances in technologies such as non-invasive diagnostic procedures and therapies. Multiple disease and the close interaction with psychological and sociocultural factors necessitate a comprehensive diagnostic approach to older people that includes psychological and social as well as medical aspects. The demographic combination of an increasing number of old people with a decreasing number of younger potential care givers makes it urgent to provide means of maintaining, improving and restoring the health and autonomy of elderly people.

\section{Political change: the emerging European Community}

The rapidly changing pattern of medical need coincides with political developments that break down traditional political and economic barriers in Europe. For members of the medical profession there will be free access to all countries within the European Community, but large regional differences in the provision of medical services to the old, as well as widely differing requirements and provisions for education and training, continue to exist.

In some European countries the need for specialized knowledge in medical gerontology has been recognized for many years, while in other countries this need has hardly been recognized at all and yet professional qualifications of any European country have to be accepted by all. In countries without a recognized specialty in medical gerontology it is none the less possible to claim status as a specialist since doctors with a training in the specialty cannot be denied access to work. The commitment of Faculties and governments to standardizing education and training in medical gerontology thus becomes a matter of concern. An

- H. B. Stähelin, E. Beregi, S. Duursma, J. Grimley Evans, J-P. Michel, A. Ruiz-Torres, B. Steen. adequate representation of medical gerontology in teaching and training in medicine throughout Europe is an important goal. The Group of European Professors in Medical Gerontology (GEPMG) has initiated preliminary discussions on this issue.

\section{Medical gerontology}

The terms 'geriatrics' or 'geriatric medicine' designate specialist clinical medical practice among older people, but do not clearly subsume the scientific study of ageing. GEMPG proposes the term 'medical gerontology' to comprise both clinical practice and the science of age $\mathrm{ng}$ in its relevance to medicine. While 'geriatrics', 'geriutric medicine' or 'psychogeriatrics' will continue to be used for the clinical practice, the more comprehensive term, medical gerontology, is more valuable in discussion, teaching and training in medical aspects of ageing.

\section{Teaching medical gerontology in Europe- the present situation}

In the spring of 1991, GEPMG sought, by postal and direct enquiry, the following information about medical faculties of the European countries:

1. Whether the faculty had professorships in gerontology, geriatrics or psychogeriatrics.

2. Whether the faculty offered undergraduate training facilities related to gerontology, geriatrics or psychogeriatrics.

3. Whether postgraduate training was offered.

4. Whether the training is subject to formal examination.

5. Whether degrees in gerontology, geriatrics or psychogeriatrics were offered.

In summary, the situation of undergraduate teaching in Europe is as follows:

(a) Chairs in geriatrics, psychogeriatrics or gerontology: Medical gerontology is well established at the undergraduate level in Scandinavian countries, the United Kingdom and to some extent in Italy. Not in all places, however, are the undergraduate courses mandatory. In Germany, Belgium, the Netherlands and Switzerland only a small percentage of the medical faculties have professorships in medical gerontology. There is some suggestion that the number could increase in the near future. At 11 French universities there are medical institutions exclusively or predominantly dedicated to geriatrics which have functions equivalent to that of 
Table I. Teaching medical gerontology in Europe

\begin{tabular}{|c|c|c|c|c|c|c|}
\hline \multirow[b]{2}{*}{ Country } & \multirow{2}{*}{$\begin{array}{l}\text { Med } \\
\text { fac }\end{array}$} & \multicolumn{3}{|c|}{ Professorial Departments in } & \multicolumn{2}{|c|}{ Curriculum } \\
\hline & & Gerı & Psger & Gero & Ugrad & Pgrad \\
\hline Austria & 3 & - & - & - & 1 & - \\
\hline Belgium & 11 & 2 & - & 1 & 5 & yes \\
\hline Bulgaria & 5 & - & - & - & - & - \\
\hline Czechoslovakia* & 10 & 1 & 1 & - & 1 & yes \\
\hline Denmark & 3 & 1 & - & - & 2 & yes \\
\hline Finland & 5 & 3 & - & 1 & 5 & yes \\
\hline France & 37 & - & 一 & 一 & 18 & yes \\
\hline Germany & 36 & 3 & 1 & 2 & 6 & yes \\
\hline Greece & 6 & - & - & - & 2 & $t$ \\
\hline Hungary & 4 & - & - & - & 2 & yes \\
\hline Iceland & 1 & - & - & - & - & - \\
\hline Ireland & 2 & 1 & - & - & 1 & yes \\
\hline Italy & 22 & 22 & - & 22 & 22 & yes \\
\hline Malta & 1 & - & - & 1 & - & $?$ \\
\hline The Netherlands & 8 & 2 & 3 & 3 & 8 & - \\
\hline Norway & 4 & 3 & 一 & - & 3 & yes \\
\hline Poland & 10 & 4 & - & 1 & 5 & yes \\
\hline Portugal & 5 & 1 & - & - & 1 & - \\
\hline Rumania & 6 & - & - & - & - & - \\
\hline Spain & 23 & - & - & 1 & 1 & yes \\
\hline Sweden & 6 & 8 & 3 & 2 & 6 & yes \\
\hline Switzerland & 5 & 2 & 1 & 1 & 2 & - \\
\hline United Kingdom & 26 & 21 & 4 & 1 & 24 & yes \\
\hline USSR* & 87 & 2 & - & - & 2 & yes \\
\hline Yugoslavia* & 11 & $?$ & $?$ & $?$ & $?$ & $?$ \\
\hline
\end{tabular}

- Former states of Czechoslovakia, USSR and Yugoslavia.

+ To be instituted in 1994.

Inventory, as of 1991 or later if data available, of medical faculties (Med fac), Professorial Departments in geriatric medicine (Geri), psychogeriatrics (Psger) or gerontology (Gero) and courses for an official undergraduate (Ugrad) and postgraduate (Pgrad) curriculum.

Professorial departments but are not formerly designated as such. In Central and Eastern European countries, professorships in medical gerontology exist in some, but not in all countries. As in the French universities, there are gerontological medical institutions not identified as Professorial departments, but fulfilling similar functions. As shown in Table I, most relevant professorships are in geriatric medicine and professorships in gerontology are far less common.

(b) Undergraduate training programmes and medical gerontology: Undergraduate training programmes are closely, but not exclusively linked to the presence of professorial departments in medical gerontology. In France, for example, 18 universities offer a course in medical gerontology, while in Spain, Italy, Germany and Switzerland, as well as in a number of Eastern European countries, teaching in medical gerontology is integrated into other parts of the medical curriculum. It was not possible to evaluate the extent of teaching which probably varies widely in size and content.

(c) Postgraduate training: Geriatrics forms by far the largest part of postgraduate training in medical gerontology. There are wide differences between countries. In Czechoslovakia, Finland, Ireland, Italy, the Netherlands, Spain, Sweden and the United Kingdom, post- graduate training in geriatric medicine leads to recognized specialist status either as a full specialty of geriatric medicine or in geriatric medicine as a subspecialty of general (internal) medicine. Several countries, for example Germany and Switzerland, aim eventually to adopt geriatrics as a subspecialty (Table II). In France, postgraduate training in geriatrics is offered on a national scale leading to certification.

In most Eastern European countries, postgraduate training is offered in some universities and institutions. Degrees are offered, but these correspond to certification. In countries with no formal recognition of geriatric medicine, training in a geriatric institution can be acceptable as part of training in general medicine, or general psychiatry as well as for general practice.

(d) Qualifications: If medical gerontology and geriatric skills are to be properly assessed they need to be part of existing examinations during medical school training. It was not apparent from our survey to what extent this is so. Postgraduate training varies widely even within countries. The United Kingdom requires an entry examination to higher specialist training in all medical specialties, but exit examinations in medical specialties are not required and indeed their introduction is at present specifically resisted by the responsible public 
Table II. Recognition of Medical Gerontology as a specialty or other forms of recognition in European countries

\begin{tabular}{ll}
\hline $\begin{array}{l}\text { Form of } \\
\text { recognition }\end{array}$ & $\begin{array}{l}\text { Number of } \\
\text { countries }\end{array}$ \\
\hline Specialty & 8 \\
Subspecialty & 3 \\
Other forms & 9 \\
No recognition & 4 \\
No information & 3 \\
\hline
\end{tabular}

- This number is likely to increase over the next two years (e.g. Greece, Rumania).

body. Exit examinations are established in Sweden, Belgium, France and Germany. Some countries require only a given time period in approvable traineeship in geriatric medicine. In Eastern European countries, universities and gerontological institutions hold final examinations. A special programme has been adopted in France where different levels of qualifications exist. These include a national programme leading to a medical competence certificate called 'Capacité de gerontologie', for junior faculty there is the 'Diplome d'études complimentaire' (DEC) which can be topped by the 'Diplome d'études approfondi' (DEA).

\section{Future action}

Our examination of present educational systems reveals the widely differing conditions of education and training in medical gerontology in Europe. In order to provide appropriate up-to-date education and training in medical gerontology certain steps seem necessary in the near future:

1. It will be of primary importance to train a junior faculty in medical gerontology to answer the increasing need. To promote this our group proposes to hold special workshop courses and summer schools where junior faculty members interested in medical gerontology can receive training.

2. Countries with well established medical gerontology training should offer practical advice on how to establish a curriculum in the subject. This is of particular importance since the rapidly growing medical specialization in other fields competes for teaching time and student interest. The commitment of faculty and administration to the inclusion of medical gerontology in curricula is of paramount importance.

3. GEPMG intends to develop a core curriculum in medical gerontology to define a minimal standard for European medical schools.

4. In postgraduate training it will be necessary to define skills as well as knowledge and attitudes in the clinical application of medical gerontology. The target group will be those specializing in geriatric medicine and psychogeriatrics, but including all physicians bearing responsibility for elderly patients. Again countries with well established curricula and postgraduate training should offer training opportunities to visiting fellows of other European countries to ensure the dissemination of skills in geriatric medicine.

5. To achieve the above goals it will be necessary to establish a professorship in medical gerontology at each medical faculty. The comprehensive nature of medical gerontology requires an independent structure, albeit with wide-ranging opportunities for interdisciplinary collaboration.

As a working group of teachers in medical gerontology from various countries with distinct social backgrounds, we realize that to attain these goals different approaches will be necessary to match the present diversity of European countries. None the less, there is an urgent need to adopt an active approach to shaping medical gerontology in the emerging Europe in order to ensure adequate care for the older members of our communities. It is from their contribution to past and present cultural and economic development that we all now benefit.

\section{References}

1. United Nations. The sex and age distribution of populations. 1990 Revision. New York: Department of International Economic and Social Affairs. S'T/ESA/SER.A/122. 1991.

2. Schramm A. Medizinische Probleme bei der Betreuung von Langlebigen. Ther Umsch 1991;48:278-84.

Authors' addresses

Hannes B. Stähelin*

Geriatrische Universıtätsklinik, Kantonsspital, 4031 Basel, Switzerland

\section{Edit Beregi}

Gerontology Centre of Semmelweiss University of Medicine, Budapest 1085, Rökk Szılárd utca 13, 1428 POB 45 Hungary

S. A. Duursma

Academisch Ziekenhuis Utrecht, Heidelberglan 100; $3584 \mathrm{CX}$ Utrecht, Postbus 85500, 35-08 GA Utrecht, The Netherlands

J. Grimley Evans

Department of Clinical Geratology, Radcliffe Infirmary, Oxford OX2 6HE, England

J-P. Michel

Institutions Universitalres de Gériatrie, Route de Mon-Idée, 1226 Thônex, Geneva, Switzerland

\section{A. Ruiz-Torres}

Department of Endocrinology and Nutrition, Institute of Gerontological Investigation, University Autónoma de Madrid, Hospital de la Princesa, Diego de León, 62-28006 Madrid, Spain

Bertil Steen

Department of Geriatric and Long-term Care Medicine, Vasa Hospital, S-41133 Gothenburg, Sweden

- Address correspondence to Professor Stähelin.

Received 1 November 1993 